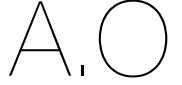

ARTIGO ORIGINAL

${ }^{1}$ Associação Portuguesa de Nutrição,

Rua João das Regras,

n. ${ }^{\circ} 284, \mathrm{R} / \mathrm{C} 3$,

4000-291 Porto, Portugal

2 ID+ Instituto de Investigação em Design,

Media e Cultura,

Departamento de

Comunicação e Arte da

Universidade de Aveiro,

Campus Universitário de

Santiago,

3810-193 Aveiro, Portugal

${ }^{3}$ Lipor,

Rua Morena, n. ${ }^{\circ} 805$

4435-996 Baguim do

Monte, Portugal

${ }^{4}$ Circular Economy

Portugal,

Tv. Pedras Negras,

n. ${ }^{\circ} 1,1 .{ }^{\circ}$ Dto.,

1100-404 Lisboa, Portugal

5 Câmara Municipal do

Porto,

Praça General Humberto

Delgado,

4049-001 Porto, Portugal

"Endereço para correspondência:

Helena Real

Rua João das Regras,

n. $284, \mathrm{R} / \mathrm{C} 3$

4000-291 Porto, Portugal

helenareal@apn.org.pt

Histórico do artigo:

Recebido a 3 de julho de 2021 Aceite a 14 de setembro de 202

\section{REFERENCIAL DE CRITÉRIOS PARA CHECKLIST DE AVALIAÇÃO DA SUSTEN- TABILIDADE EM RESTAURANTES}

\author{
CRITERIA REFERENTIAL TO EVALUATION CHECKLIST OF \\ SUSTAINABILITY IN RESTAURANTS
}

Helena Real1*; Sílvia Soares²; Cristina Ferreira ${ }^{3}$; Luisa Marques ${ }^{4}$; Teresa Fonseca Gonçalves ${ }^{5}$

\section{RESUMO}

INTRODUÇÃO: O sistema alimentar é o maior consumidor de recursos naturais finitos do planeta, sendo responsável por cerca de $26 \%$ das emissões globais de gases de efeito de estufa. A produção alimentar não sustentável é também responsável pela desflorestação, perda de biodiversidade e de qualidade dos solos, danos que ultrapassam a capacidade regenerativa do Planeta. Além disso, as más escolhas alimentares são também responsáveis por um impacte negativo no nosso Planeta e paralelamente na saúde de quem pratica um padrão alimentar mais desequilibrado. Urge intervir neste sistema, procurando promover a sua transformação para um sistema mais sustentável e equilibrado. Neste âmbito, será importante envolver os diversos agentes do sistema alimentar, onde os restaurantes se afiguram como um elemento de relevo.

OBJETIVOS: Compilar e analisar uma listagem com os principais critérios de sustentabilidade com base em listagens pré-existentes de critérios e de selos no âmbito da sustentabilidade, da produção e consumo alimentares, para desenvolvimento de um referencial de avaliação para aplicação em restaurantes.

METODOLOGIA: Foram compilados os critérios referentes a 13 listagens de selos ou listagens de critérios de sustentabilidade, dirigidos para o setor da restauração. Realizou-se uma análise pormenorizada de todos os critérios, sobre a sua redundância, especificidade ou repetição entre critérios de listas diferentes e eliminaram-se, adicionalmente, todos os critérios que consideravam procedimentos de caráter obrigatório, por via da legislação nacional ou comunitária.

RESULTADOS: Obteve-se uma listagem final com 160 critérios de sustentabilidade, divididos por 9 domínios: Produção Alimentar; Ementa; Embalagens; Água; Energia; Consumíveis; Instalações e Equipamentos; Transporte; Colaboradores, Comunicação, Responsabilidade Social.

CONCLUSÕES: A listagem obtida com os principais critérios de sustentabilidade para aplicação em restaurantes portugueses ou europeus pretende representar uma ferramenta que os auxilie num processo de reestruturação do seu modelo ou num processo de construção de um novo conceito mais sustentável, à semelhança de projetos que começam a surgir no mercado.

\section{PALAVRAS-CHAVE}

Consumo alimentar, Dieta Mediterrânica, Economia circular, Listagem de critérios, Produção alimentar, Restaurantes, Sustentabilidade

ABSTRACT

INTRODUCTION: Food systems are the largest consumers of finite natural resources on the planet, accounting for about $26 \%$ of global greenhouse gas emissions. Unsustainable food production is also responsible for deforestation, loss of biodiversity and soil quality, damage that goes beyond the planet's regenerative capacity. In addition, poor food choices are also responsible for a negative impact on our planet and at the same time on the health of those who practice a more unbalanced food pattern. There is an urgent need to intervene in this system, seeking to promote its transformation into a more sustainable and balanced system. In this context, it is critical to involve the various agents of the food system, where restaurants appear to be an important element. OBJECTIVES: To compile and analyze a checklist with the main sustainability criteria based on pre-existing lists of criteria and certificates in the field of sustainability, food production and consumption, for development of a evaluation referential to application in restaurants. METHODOLOGY: The criteria have been compiled for 13 sustainability certificate listings or sustainability criteria listings for the food service sector. A detailed analysis of all criteria, on their redundancy, specificity or repetition between different list criteria, was carried out and, in addition, all criteria that considered procedures of a mandatory nature through national or community legislation were eliminated.

RESULTS: A final list was obtained with 160 sustainability criteria, divided into 9 domains: Food Production; Menu; Packaging; Water; Energy; Consumables; Facilities and Equipment; Transport; Employees, Communication, Social Responsibility.

CONCLUSIONS: The checklist obtained with the main sustainability criteria for application in Portuguese or European restaurants intends to represent a tool to help them in the process of restructuring their model or in the process of building a new more sustainable concept, similar to projects that are beginning to appear in the market.

KEYWORDS

Food consumption, Mediterranean Diet, Circular economy, Checklist, Food production, Restaurants, Sustainability 


\section{INTRODUÇÃO}

Alimentos não saudáveis e produzidos de forma insustentável representam um risco a nível global para o ser humano e para o planeta (1). O sistema alimentar é o maior consumidor de recursos naturais finitos do planeta e é responsável por cerca de $26 \%$ das emissões globais de gases de efeito de estufa que estão a provocar a emergência climática global (2), estimando-se um aumento das emissões de gases de efeito de estufa no setor alimentar em cerca de 38\% até 2050 (3). A agricultura é responsável pela alteração significativa de cerca de $75 \%$ da terra habitável do mundo (sem gelo e deserto) (4), $78 \%$ da eutrofização dos oceanos e água doce (2), perda de 85\% dos pântanos, desflorestamento e perda de biodiversidade (4). Das 28.000 espécies identificadas em ameaça de extinção pela Lista Vermelha da International Union for Conservation of Nature, a agricultura e a aquicultura constituem uma ameaça para 24.000 delas (2). A crescente perda de biodiversidade, para além de constituir um problema ambiental, constitui um problema de desenvolvimento sustentável, segurança alimentar, ética e moral, e de muitos serviços de ecossistemas vitais, pelo que a sua contínua perda constitui uma ameaça à espécie humana (5).

Simultaneamente, as tendências dos padrões alimentares estão a tornar a nossa sociedade mais doente e menos produtiva (6). Ao mesmo tempo que o consumo de alimentos de origem animal representa aproximadamente $75 \%$ das emissões de gases de efeito de estufa a nível alimentar (2), o seu consumo excessivo, assim como o de alimentos muito processados ricos em açúcar, gordura e sal estão a contribuir para o aumento das taxas de doenças cardiovasculares, obesidade, diabetes e cancro, aumento dos custos em saúde, e milhões de mortes prematuras a cada ano (7). A má alimentação é a principal causa de mortalidade e morbilidade a nível mundial, causando por ano mais de 11 milhões de mortes, de todas as mortes entre a população adulta (8). Paralelamente, debatemo-nos com a problemática do desperdício alimentar, desde a produção ao consumo alimentar. O desperdício de alimentos é um problema global com elevados custos económicos, éticos e ambientais. Em 2021, um relatório do United Nations Environment Programme apresentou uma estimativa de 931 milhões de toneladas de alimentos desperdiçados em 2019, sendo que $61 \%$ corresponde ao desperdício ocorrido em casa, 26\% ocorrido nas unidades de restauração e 13\% corresponde à distribuição (9). No que se refere à União Europeia (EU-28), estima-se que cerca de 88 milhões de toneladas de alimentos são perdidos ou desperdiçados, o equivalente a $20 \%$ de todos os alimentos produzidos, representando um valor perdido para a economia europeia no valor de 143 mil milhões de euros (10). A União Europeia é responsável pela perda de 12\% do total de alimentos produzidos por ano, correspondendo a 10,5 milhões de toneladas de resíduos alimentares (equivalente a $21 \mathrm{~kg}$ por pessoa/ano) (10). Nos restaurantes, por exemplo, são vários os fatores atribuídos ao desperdício de alimentos, entre os quais se destacam a preparação (45\%), a deterioração dos alimentos (21\%) e as sobras dos pratos dos clientes (34\%) (11)

O desperdício alimentar representa uma falha do mercado, pelo que o seu combate representa uma oportunidade para reduzir os impactes ambientais e o uso de recursos ao longo do sistema alimentar, e melhorar a segurança alimentar global, conjugando-se com a necessidade de alimentar de forma saudável e sustentável uma população mundial em crescimento que se prevê atingir os 8,6 mil milhões de pessoas em 2030 e os 9,8 mil milhões em 2050 (12). Face à dimensão do problema, em 2015, no âmbito dos Objetivos de Desenvolvimento Sustentável (ODS) e da Agenda 2030, no contexto das Nações Unidas, foi estabelecido como um objetivo fundamental a redução do desperdício alimentar para metade, per capita, a nível mundial, de retalho e de consumidor, e ao longo das cadeias de produção e abastecimento até 2030 (Objetivo 12.3 dos Sustainable Development Goals (13)).

A redução do desperdício alimentar e o alcance de sistemas alimentares mais saudáveis, sustentáveis e inclusivos, estão no centro da nova estratégia de crescimento da União Europeia "Do prado ao prato" (14), que constitui a pedra angular do "Pacto Ecológico Europeu", que define as ações para tornar a Europa o primeiro continente com impacto neutro ou positivo no clima até 2050 (15). Este define uma nova estratégia de crescimento económico dissociado da utilização de recursos baseada na neutralidade carbónica, na transição para energias renováveis, para uma economia mais verde, mais circular, na recuperação da biodiversidade e na investigação para uma utilização mais eficiente dos seus recursos. Esta estratégia representa a ação da Comissão Europeia para alcançar os Objetivos de Desenvolvimento Sustentável.

A aplicação dos princípios de Economia Circular à indústria alimentar, oferece oportunidades principalmente ao nível da valorização de fluxos biológicos inspiradas nos mecanismos naturais regenerativos. Tal como na Natureza, alimentos não consumidos, alimentam o solo e suportam a biodiversidade. Adicionalmente, estratégias que promovam o fecho de ciclos são aplicáveis a fluxos de água, energia ou outros materiais técnicos presentes e utilizados em restaurantes (materiais de construção, equipamentos, entre outros). O "Plano de Ação para a Economia Circular" da União Europeia contempla ações no âmbito da minimização de desperdício alimentar, substituição de embalagens e loiça de plástico de utilização única (16).

Segundo a Food and Agriculture Organization (FAO) (17) "um sistema alimentar sustentável é um sistema alimentar que oferece segurança alimentar e nutricional para todos de forma que as bases económicas, sociais e ambientais para gerar segurança alimentar e nutricional para as gerações futuras não sejam comprometidas. Isso significa ser rentável ao longo do tempo (sustentabilidade económica), ter amplos benefícios para a sociedade (sustentabilidade social), e ter um impacto positivo ou neutro no ambiente natural (sustentabilidade ambiental)" (tradução inglês-português proposta pelas autoras).

Um consumo sustentável passa pela implementação de uma dieta saudável e sustentável, o que constitui um dos maiores desafios das próximas décadas. Willet et al, num relatório publicado na Lancet em 2019, refere que é urgente uma transformação do sistema alimentar, defendendo um modelo alimentar para o Antropoceno (1). A dieta proposta, apresenta várias características que se assemelham à Dieta Mediterrânica (18), sendo esta caracterizada pela escolha alimentar à base de alimentos de origem vegetal e de pouca quantidade $e$ frequência de alimentos de origem animal, com o uso de azeite como gordura de adição de eleição, opção preferencial por cereais integrais, recurso a ervas aromáticas em detrimento do sal, uso reduzido de produtos muito processados, revelando-se preocupações com a origem de uma produção alimentar mais sustentável, e inserindo-se num modelo global cultural, onde também se dá particular realce à convivialidade em redor da mesa e ao estilo de vida das pessoas. Pela junção destas características, a Dieta Mediterrânica é reconhecida como um dos modelos alimentares mais saudáveis e sustentáveis (19, 20). Os restaurantes são um importante ator em toda esta equação, tendo-se vindo a registar uma forte tendência no surgimento de restaurantes mais sustentáveis. Muitos investidores da área da restauração têm vindo a promover este tipo de estabelecimento, seja pelo facto de oferecer comida saudável preparada com alimentos provenientes de produção sustentável, ou até mesmo pelo facto de utilizar os recursos de forma mais responsável e eficiente e reduzir os custos operacionais, aumentando a rentabilidade. 
Esta preocupação com o desenvolvimento sustentável é acompanhada também por parte dos consumidores, os quais têm vindo a assumir um papel cada vez mais determinante para o impulsionamento do consumo sustentável, levando a uma mudança de atitude e tendências ao nível do empreendedorismo sustentável (Cruz, 2016). Segundo dados do Segundo Grande Inquérito sobre Sustentabilidade, de 2019, os consumidores portugueses revelam estar mais motivados para serem mais sustentáveis, denotando-se pelo facto de considerarem o desperdício alimentar no topo das suas preocupações relacionadas com os alimentos, por exemplo, contudo, por outro lado, mantém um consumo elevado de produtos de origem animal e revelam um baixo reconhecimento dos símbolos de práticas de produção sustentável (21). Desta forma, perante uma aceitação acrescida por parte dos consumidores, urge adensar as medidas que promovam a sensibilização da população e de todos os agentes envolvidos no sistema alimentar bem como que ofereçam soluções efetivas para a problemática.

Para além dos impactes ambientais positivos resultantes de um sistema alimentar mais sustentável, este pode ser também responsável por benefícios económicos tangíveis para os restaurantes: poupança resultante da eliminação/redução de desperdício de alimentos edíveis (22); poupança em despesas de energia através da implementação de medidas simples de eficiência energética (23); cumprir com legislação a ser implementada nomeadamente em termos de plásticos de uso único ou recolha seletiva de bio-resíduos. Restaurantes sustentáveis têm ainda a potencialidade de apelar a um grupo de consumidores conscientes, e servirem de inspiração a outros estabelecimentos. Existem já alguns exemplos de restaurantes nacionais e internacionais reconhecidos pelo seu carácter sustentável como o restaurante "A Cozinha" (Guimarães, Portugal) (24); restaurante "Kitchen Dates" (Lisboa, Portugal) (25); restaurante "Nolla" (Helsínquia, Finlândia) (26), restaurante "Silo" (Londres, Reino unido) (27) ou restaurante "Azurmendi" (Larrabetzu, Espanha) (28).

Apesar de existirem diversos selos ou listas de verificação destinadas a valorizar a sustentabilidade, o equilíbrio nutricional ou a produção sustentável, não existe nenhuma ferramenta que congregue de forma extensiva cada um destes componentes e que os ajuste ao Padrão Alimentar Mediterrânico, no contexto de um restaurante, de forma a veicular um serviço promotor de maior saúde, pelo que este trabalho pretende dar resposta a esta matéria, com base em ferramentas já existentes.

Dados de 2019, indicam que em Portugal existiam 32293 restaurantes, onde trabalhavam 170790 colaboradores, correspondendo 99,4\% a micro ou pequenas empresas, 0,5\% a médias empresas e 0,1\% a grandes empresas (29). neste sentido, há um grande mercado a trabalhar e que pode representar um veículo considerável de sustentabilidade.

\section{OBJETIVOS}

Compilar e analisar uma listagem com os principais critérios de sustentabilidade com base em listagens pré-existentes de critérios e de selos no âmbito da sustentabilidade, da produção e consumo alimentares, para desenvolvimento de um referencial de avaliação para aplicação em restaurantes.

\section{METODOLOGIA}

Para a construção da listagem de critérios sobre sustentabilidade a implementar em restaurantes foi efetuada uma pesquisa, entre outubro e novembro de 2020, no Google Scholar usando os descritores "checklist for restaurants"; "sustainability restaurants checklist"; "critérios de sustentabilidade na restauração"; "checklist de sustentabilidade na restauração"; "listas de verificação".

Para além disso, com base no melhor conhecimento das autoras, foram recolhidos critérios de selos e listagens que remetessem diretamente para o conceito da sustentabilidade ou temáticas adjacentes, como a circularidade, a Dieta Mediterrânica, a Alimentação Saudável ou a produção local, necessárias na restauração coletiva social e comercial, nomeadamente de: Establecimientos Promotores de la Alimentación Mediterránea (30); Food that doesn't cost the Earth (31); Green Globe (32); Green Key (33); Lista de verificação de boas práticas ambientais para serviços de alimentação (34); Projeto "Embrulha" (35); Selo "Dose Certa" (36); Selo "Restaurante FOOD" (37); Selo 100\% local (informação cedida pela Associação InLocco); Selo Agir Saudável - Serviços de alimentação (38); Selo de excelência "Alimentação Saudável no Ensino Superior" (39); Selo Saudável (40); Sustainability indicators in foodservice (41).

Os critérios das listagens foram agregados mantendo-se o texto original, bem como a dimensão a que pertenciam, sempre que aplicável. De forma a uniformizar a categorização dos critérios as autoras entenderam definir os seguintes nove domínios: Produção Alimentar; Ementa; Embalagens; Água; Energia; Consumíveis; Instalações e Equipamentos; Transporte; Colaboradores, Comunicação, Responsabilidade Social, mantendo-se as dimensões iniciais, criando-se novas ou atribuindo dimensões de novo aos critérios não categorizados na listagem de base, de forma a constituir um quadro de referência para a realização de checklists de aplicação prática.

Tendo em conta o número de critérios das listagens consultadas e para não se apresentar uma listagem exponencialmente superior, foi fixado um limite de 150-175 critérios para a listagem final a propor. Esta meta conduziu a um trabalho de análise pormenorizado de todos os critérios, sobre a sua redundância, especificidade ou repetição entre critérios de listas diferentes. Além disso, destinando-se este trabalho a uma potencial aplicação em contexto nacional ou europeu, eliminaram-se os critérios que consideravam procedimentos de caráter obrigatório, por via da legislação nacional ou comunitária em vigor (p.e. relativos a higiene e segurança alimentar). Foram também eliminados critérios cuja aplicação não fosse adequada ao caso Europeu. Por outro lado, sempre que se entendeu necessário, complementou-se a informação de determinados critérios com conteúdo de critérios de listagens iniciais diferentes, ou com exemplos práticos, considerando-se nestes casos o uso de dois ou mais critérios para efeito de contagem final de critérios usados. Tendo em conta que no conjunto de listagens apenas existia uma que foi sujeita a um processo de validação científica ("Sustainability Indicators in Foodservice" (41)), definiu-se que em situações de semelhança entre critérios, se mantinha o texto do critério proveniente desta listagem validada. Foram ainda incluídos critérios construídos de novo, com base na proposta das autoras, bem como critérios que resultam da pesquisa e adaptação do conteúdo de documentos de referência, como o Green Public Procurement criteria for food, catering services and vending machines (42).

No final foi realizada uma uniformização de linguagem dos critérios para efeitos de tradução de uma maior coerência do conteúdo da listagem total e que refletisse uma abordagem virada para a ação/ transformação e não em formato normalmente presente em lista de verificação de auditorias. Os critérios provenientes de listagens publicadas em inglês foram traduzidos para português por meio de tradução simples. 


\section{RESULTADOS}

Da pesquisa efetuada obtiveram-se 13 listagens de critérios que encaixam no conceito de sustentabilidade, com aplicação em restaurantes, num total de 498 critérios, promovidas por diferentes entidades/autores e referentes a diversos países (Tabela 1).

Após a atribuição de domínio a cada critério e sua respetiva revisão para ajuste de linguagem e conteúdo, obtiveram-se 160 critérios finais (Tabela 1). Na Tabela 2, é apresentada a listagem final de critérios, distribuídos por nove domínios, mantendo-se a indicação da origem do critério e adicionando-se um total de 14 critérios propostos pelas autoras.

O domínio da Produção Alimentar é caracterizado por um conjunto de critérios que evidenciam a relevância da produção no âmbito do ciclo de vida do alimento, tendo em conta aspetos fundamentais como: sazonalidade; origem; produção de proximidade e as cadeias curtas de distribuição e produção alimentar com práticas sustentáveis.

O domínio da Ementa envolve os critérios a ter em conta desde o momento da receção dos produtos alimentares adquiridos, passando pela preparação dos alimentos e sua confeção, até ao momento do consumo pelos clientes do restaurante, procurando realçar a importância da qualidade nutricional das confeções, baseada nos princípios do Padrão Alimentar Mediterrânico. Inclui ainda elementos sobre a forma de apresentação da ementa aos clientes ou como gerir o desperdício alimentar e os resíduos orgânicos.

O domínio das Embalagens integra não só critérios de embalagens de produtos que entram no restaurante, mas também das embalagens de doses individuais e de takeaway.

O domínio da Água inclui os critérios que permitem logo desde a conceção da instalação do seu fornecimento, o investimento e instalação de produtos e tecnologia de poupança de água, a sua monitorização, conselhos e boas práticas no seu uso e poupança, bem como o respetivo tratamento após o uso, de forma a se reaproveitar para posterior reutilização, quando possível.
De igual modo, o domínio da Energia envolve os critérios que permitem desde a conceção da instalação, do seu fornecimento, o investimento e instalação de produtos e tecnologia de poupança de energia, a sua monitorização, opção por fontes energéticas mais sustentáveis e amigas do ambiente, energias menos poluentes, conselhos e boas práticas na sua utilização e poupança.

O domínio dos Consumíveis envolve um conjunto de critérios transversais que destacam a importância do recurso a alternativas que sejam reutilizáveis, recicláveis ou sustentáveis, desde a aquisição de produtos de higienização, utensílios e louças até ao próprio vestuário dos colaboradores.

O domínio das Instalações e Equipamentos inclui os critérios desde o design da conceção das instalações e mobiliário, os materiais a usar, mais amigos do ambiente, a sua posterior renovação e integração, e a sua eventual reutilização.

O domínio dos Transportes integra os meios utilizados pelos fornecedores, mas também pelo próprio restaurante.

E por fim, o domínio dos Colaboradores, Comunicação, Responsabilidade Social envolve um conjunto de critérios dedicados aos colaboradores do restaurante, focando, desde a sua integração na equipa até à formação que Ihes é disponibilizada; inclui ainda uma dimensão sobre a Comunicação do restaurante para o cliente e para o exterior sobre sustentabilidade, saúde, bem como sobre a comunicação das suas medidas implementadas aos clientes. Este domínio integra ainda a dimensão da Responsabilidade Social, sendo caracterizada pelas ações que o restaurante desenvolve com vista a uma maior promoção da sustentabilidade na sua comunidade envolvente, bem como o realce da componente social que o restaurante pode dinamizar.

\section{Tabela 1}

Caracterização do conjunto de listagens de critérios de sustentabilidade recolhidos

\begin{tabular}{|c|c|c|c|c|c|}
\hline LISTA DE CRITÉRIOS & $\begin{array}{l}\text { ENTIDADE } \\
\text { PROMOTORA/AUTORES }\end{array}$ & PAÍS DE APLICAÇÃO & $\begin{array}{c}\text { ANO DE } \\
\text { DESENVOLVIMENTO/ } \\
\text { EDIÇÂAO }\end{array}$ & $\begin{array}{l}\text { N. } .^{\circ} \text { DE CRITÉRIOS DA } \\
\text { LISTA ORIGINAL }\end{array}$ & $\begin{array}{l}\text { N. }{ }^{\circ} \text { DE CRITÉRIOS } \\
\text { UTILIZADOS PARA A } \\
\text { LISTAGEM GERAL }\end{array}$ \\
\hline $\begin{array}{l}\text { Establecimientos promotores de la } \\
\text { Alimentación Mediterránea }\end{array}$ & Amed-Alimentació Mediterrània & Espanha & 2007 & 20 & 14 \\
\hline Food that doesn't cost the Earth & London Waste and Recycling Board & Reino Unido & 2020 & 60 & 24 \\
\hline Green Globe & Green Globe Ltd UK & Internacional & 1999 & 39 & 13 \\
\hline Green Key & $\begin{array}{l}\text { Foundation for Environmental } \\
\text { Education/ABAE }\end{array}$ & $\begin{array}{l}\text { Internacional, com } \\
\text { aplicação em Portugal }\end{array}$ & 1994 & 117 & 51 \\
\hline $\begin{array}{l}\text { Lista de verificação de boas práticas } \\
\text { ambientais para serviços de alimentação }\end{array}$ & Luciléia Colares et al. & Brasil & 2018 & 68 & 6 \\
\hline Projeto "Embrulha" & Lipor & Portugal & 2016 & 4 & 1 \\
\hline Selo "Dose Certa" & Lipor & Portugal & 2016 & 8 & 2 \\
\hline Selo "Restaurante FOOD" & FOOD /Direção-Geral da Saúde & $\begin{array}{l}\text { Internacional, com } \\
\text { aplicação em Portugal }\end{array}$ & 2012 & 23 & 1 \\
\hline Selo $100 \%$ local & Associação InLocco & Portugal & 2018 & 6 & 3 \\
\hline $\begin{array}{l}\text { Selo Agir Saudável - Serviços de } \\
\text { alimentação }\end{array}$ & Bioqualitas PR & Brasil & 2011 & 35 & 13 \\
\hline $\begin{array}{l}\text { Selo de excelência "Alimentação } \\
\text { saudável no ensino superior" }\end{array}$ & Direção-Geral da Saúde & Portugal & 2019 & 16 & 3 \\
\hline Selo saudável & $\begin{array}{c}\text { Direção-Geral da Saúde e Câmara } \\
\text { Municipal de Lisboa }\end{array}$ & Portugal & 2016 & 26 & 3 \\
\hline $\begin{array}{l}\text { Sustainability indicators in } \\
\text { foodservice }\end{array}$ & Dayanne Maynard et al. & Brasil & 2020 & 76 & 36 \\
\hline \multirow[t]{2}{*}{ Proposta das autoras } & & & 2020 & & 14 \\
\hline & & & TOTAL & 498 & $184^{*}$ \\
\hline
\end{tabular}

*Este número corresponde ao número total de itens usados de todos os domínios, sendo que alguns critérios foram condensados em critérios únicos, correspondendo a um número final de 160 critérios. 
Lista final de critérios de sustentabilidade para aplicação em restaurantes portugueses, divididos pelos domínios propostos

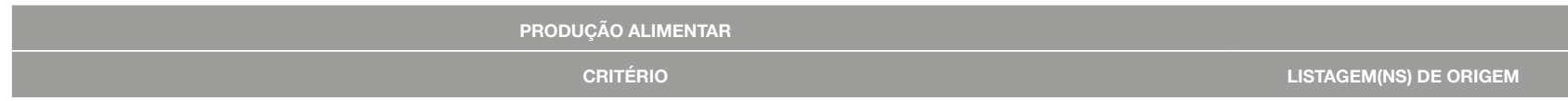

Cultivar os seus próprios alimentos em jardins ou hortas junto ao restaurante Food that doesn't cost the Earth*

Privilegiar a escolha de fornecedores que pratiquem boas práticas na produção, manuseamento e/ou transformação dos produtos locais, nomeadamente no que se refere a: i) manter os recursos naturais, preservando a água e o solo; ii) aplicar produtos fitofarmacêuticos de acordo com a legislação em vigor, não comprometendo a saúde do consumidor

Privilegiar a escolha de produção local (num raio de $75 \mathrm{Km}$ ) regional e/ou nacional, respeitando a sazonalidade

Selo $100 \%$ Local

Planear compras de produtos frescos locais em menor quantidade e maior frequência, por forma a diminuir o período de armazenamento manter a frescura e reduzir o desperdício alimentar

Privilegiar a escolha de alimentos sazonais, preferencialmente cultivados ao ar livre

Privilegiar a escolha de produtos alimentares/bebidas biológicos, com rótulo ambiental, de comércio justo e/ou produzidos localmente

Comprar produtos frescos agrícolas num raio de $75 \mathrm{Km}$

Visitar periodicamente os locais de produção dos produtos alimentares a usar no estabelecimento

Privilegiar a utilização de ovos com código 1 e/ou 3

Considerar a aquisição de produtos com sistemas de qualificação (por exemplo: IGP, DOP), animais e plantas autóctones, sempre que produzidos em proximidade

Ter sistemas de pedidos inteligentes, monitorização de stocks, rotação de stocks e/ou outras estratégias de gestão de stocks para evitar o desperdício alimentar

Encaminhar o resultado do processo de compostagem própria para produtores locais

Entregar resíduos verdes a produtores agrícolas para compostagem ou alimentação animal

Selo $100 \%$ Local + Selo Saudável ${ }^{\star}$

Proposta das autoras

Selo $100 \%$ Local $^{\star \star}$

Green Key

Proposta das autoras

Proposta das autoras

Proposta das autoras ${ }^{\star \star}$

Proposta das autoras

Sustainability Indicators in Foodservice Proposta das autoras Proposta das autoras

\begin{tabular}{l} 
EMENTA \\
CRITÉRıIO \\
\hline Comprar ingredientes que de outra forma seriam desperdício (por exemplo: frutas ou hortícolas de calibre ou formato irregular) \\
\hline Eliminar o consumo de carne e pescado e outras espécies ameaçadas ou em risco de extinção \\
\hline Desenvolver e usar fichas técnicas dos pratos do menu na sua preparação \\
\hline Fornecer acima de $50 \%$ dos pratos com equilíbrio nutricional \\
\hline Priorizar o aproveitamento integral dos alimentos, produzindo preparações seguras que utilizem cascas, talos e/ou outras partes edíveis \\
de hortícolas e frutas como ingredientes
\end{tabular}

Ter compromissos documentados, com prazo definido, sobre a redução do uso de açúcar, sal ou gordura saturada do menu

Ter preparações culinárias que não requeiram a adição de grande quantidade de gordura e utilizar técnicas que preservem os nutrientes dos alimentos, como cozimento a vapor, salteado, estufado, caldeirada, açordas, ensopados, sopas, etc.

Garantir que o azeite seja usado para temperar, em qualquer uma das suas variedades, e que seja utilizado azeite para cozinhar ou óleo de girassol com alto teor de ácido oleico

Incluir na ementa propostas da gastronomia tradicional e local

Food that doesn't cost the Earth*

$$
\text { Green Key }
$$

Sustainability Indicators in Foodservice

Sustainability Indicators in Foodservice*

Sustainability Indicators in Foodservice

Sustainability Indicators in Foodservice*

Establecimientos Promotores de la Alimentación Mediterránea*

Establecimientos Promotores de la Alimentación Mediterránea

Establecimientos Promotores de la Alimentación Mediterránea

Establecimientos Promotores de la Alimentación Mediterránea*

Garantir a presença de pelo menos um produto à base de cereais integrais (pão, massa, arroz ou outros)

Establecimientos Promotores de la Alimentación Mediterránea*

Priorizar a oferta alimentar de produtos hortícolas

Utilizar uma variedade diversificada de ingredientes de origem vegetal

Reduzir a quantidade da carne e dos produtos lácteos na oferta alimentar do menu

Food that doesn't cost the Earth*

Food that doesn't cost the Earth*

Selo de Excelência "Alimentação

saudável no ensino superior" + Selo

de Excelência "Alimentação saudável no ensino superior"*

Disponibilizar pão produzido com farinha(s) integral(ais) e com um teor de sal inferior a $1 \mathrm{~g}$ por $100 \mathrm{~g}$, se contemplado no menu

Establecimientos Promotores de

la Alimentación Mediterránea +

Oferecer a opção de alguns pratos mediterrânicos combinados que podem ser propostos como um prato único e/ou a possibilidade de pedir meias porções ou menu infantil, que respeitem o equilíbrio nutricional (no caso de restaurantes com outras tipologias de oferta para além da Mediterrânica)

Adequar as quantidades das doses, bem como as proporções dos grupos alimentares, de cada prato à população alvo, mediante as recomendações do país (no caso de Portugal a referência seria a Roda da Alimentação Mediterrânica)

Proposta das autoras

Oferecer sempre água potável não engarrafada e de forma gratuita

Establecimientos Promotores de la Alimentación Mediterránea

Garantir a disponibilização de copos ou unidades individuais, em relação ao possível consumo, de bebidas alcoólicas (vinho, espumante Establecimientos Promotores de la ou cerveja)

Não disponibilizar ou reduzir gradualmente a existência de bebidas menos sustentáveis, como os refrigerantes Alimentación Mediterránea

Proposta das autoras

Fornecer sopa que seja constituída por uma base de hortícolas, podendo também ser composta por leguminosas (feijão, grão, ervilha, lentilha)

Oferecer um menu separado ou substituições para atender a restrições alimentares, como confeções sem glúten, pratos vegetarianos ou vegan ou confeções para atender as restrições religiosas

Oferecer a possibilidade de adicionar a pratos aos quais não foi adicionado sal (“opções sem sal"), temperos alternativos (pimenta, especiarias, ervas aromáticas, etc.)

Garantir que pelo menos $25 \%$ da oferta das entradas seja à base de produtos hortícolas

Selo Saudável*

Sustainability Indicators in Foodservice*

Establecimientos Promotores de la Alimentación Mediterránea

Establecimientos Promotores de la Alimentación Mediterránea

Garantir que aproximadamente $50 \%$ da oferta dos pratos principais que forneçam carne ou pescado contenham: peixes (magros ou gordos) e / ou mariscos, ou carnes magras (com baixo teor de gordura)

Establecimientos Promotores de la Alimentación Mediterránea* 
Tabela 2

Continuação

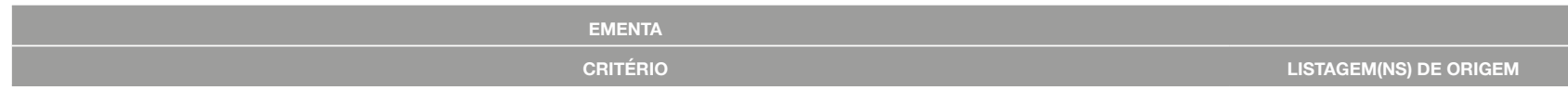

Garantir que aproximadamente $50 \%$ das ofertas de sobremesas sejam à base de frutas frescas (inteiras ou manipuladas, por exemplo, salada de frutas), e que apareçam no menu antes das sobremesas doces

Oferecer azeite virgem em galheteiros de mesa e incentivar a apresentação de rotulagem ou a identificação do grau, tipo de azeitona e origem

Não apresentar saleiros nas mesas, disponibilizar apenas se for pedido

Identificar no menu ou no buffet os produtos biológicos, com certificado ambiental, de comércio justo e/ou produzidos localmente

Enfocar o nome dos pratos na componente de origem vegetal em detrimento da componente de origem animal, quando esta existe

Identificar no menu ou no buffet a declaração nutricional e/ou outras ferramentas que permitam um maior conhecimento sobre cada sugestão gastronómica apresentada

Incluir no menu informação que permita verificar o cumprimento das recomendações do guia alimentar nacional (ex: Roda da Alimentação Mediterrânica no caso de Portugal)

Identificar no menu ou no buffet o valor do impacte ambiental de cada sugestão gastronómica apresentada (pegada de carbono ou outro)

Fazer uma avaliação periódica do desperdício alimentar durante a preparação dos pratos e consumo dos clientes

stablecimientos Promotores de la Alimentación Mediterránea*

Establecimientos Promotores de la Alimentación Mediterránea

Selo "Restaurante Food"* Green Key*

Proposta das autoras

Proposta das autoras

Proposta das autoras Proposta das autoras

Sustainability Indicators in Foodservice + Sustainability Indicators in Foodservice*

Separar os resíduos orgânicos (frutas, verduras, legumes, cascas de ovos, massas, café, chás, folhas, palhas, flores e aparas de madeira) Selo Agir Sustentável - Serviços de para compostagem própria ou todos os resíduos orgânicos para compostagem industrial Alimentação*

Realizar o tratamento dos resíduos sólidos e líquidos gerados no serviço de alimentação

Lista de verificação de boas práticas ambientais para serviços de alimentação*

Estabelecer metas de redução/controlo do desperdício alimentar

Sustainability Indicators in Foodservice ${ }^{*}$

Incentivar os seus clientes a adotar hábitos de consumo sustentáveis, levando as sobras da refeição para casa evitando o seu desperdício, em embalagens biodegradáveis gratuitas

Projeto Embrulha *

Encaminhar produtos alimentares não consumidos para iniciativas com ou sem fins lucrativos para minimizar/evitar o desperdício alimentar Sustainability Indicators in Foodservice*

EMBALAGENS
CRITÉRIO
LISTAGEM(NS) DE ORIGEM

Limitar a utilização de embalagens, optando por comprar produtos a granel, produtos sem embalagem secundária, ou recargas e trabalhar com a sua cadeia de abastecimento para reduzir as embalagens em trânsito

Privilegiar o fornecimento de produtos em embalagens retornáveis, ou alternativamente, recicláveis

Descontinuar a venda de produtos em embalagens de utilização única e embalagens individuais. Em caso de necessidade, privilegiar embalagens recicláveis

Food that doesn't cost the Earth*

Não usar embalagens descartáveis ou adotar estratégias para minimizar o seu uso ao estritamente necessário, tal como em serviços de takeaway ou de catering dando preferência a materiais biodegradáveis

Criar ou aderir a um esquema de reutilização/recuperação de embalagens de takeaway e incentivar os seus clientes a aderirem Food that doesn't cost the Earth*

Food that doesn't cost the Earth + Green Key*

Green Key + Sustainability Indicators in Foodservice*

Facilitar a reciclagem de embalagens aos clientes através da criação de um ponto de recolha de reciclagem para os produtos que os seus clientes não podem reciclar facilmente em casa ou em viagem

Food that doesn't cost the Earth*

Separar as embalagens para reciclagem

Food that doesn't cost the Earth*

Food that doesn't cost the Earth*

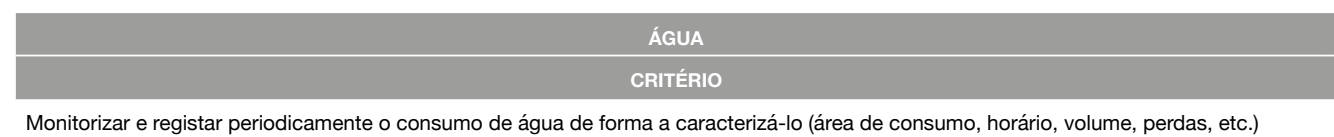

Instalar contadores da água (hidrómetros) individuais por áreas distintas de utilização

LISTAGEM(NS) DE ORIGEM

Green Key* + Green Globe*

Lista de verificação de boas práticas ambientais para serviços de alimentação*

Limitar o uso de água por atividade (com metas para o seu uso racional, por exemplo: a cada refeição servida são gastos 10 litros de água) e evitar o desperdício

Implementar práticas e políticas de poupança de água

Investir em produtos e tecnologia de poupança de água como: temporizadores, sensores ou ativação automática, reguladores de pressão e arejadores nas torneiras e chuveiros para controlar o fluxo de água

Sustainability Indicators in Foodservice* + Selo "Dose Certa"* Food that doesn't cost the Earth

Food that doesn't cost the Earth + Green Key + Selo Agir Sustentável - Serviços de Alimentação +

Equipar os urinóis com sensores e sistemas de poupança de água

Sustainability Indicators in Foodservice*

Optar por sanitas com um sistema acoplado de dupla descarga ou com acionamento seletivo para a quantidade de água Green Key*

Selo Agir Sustentável - Serviços de Alimentação*

Escolher as máquinas de lavar loiça com consumos até 3,5 litros de água por ciclo

Adquirir novas máquinas de lavar loiça e roupa que não sejam equipamentos do tipo doméstico convencional Green Key

Green Key

Só ligar a máquina de lavar louça quando estiver cheia

Selo Agir Sustentável - Serviços de Alimentação*

Monitorizar regularmente, durante a limpeza, eventuais fugas de água na rede de abastecimento, torneiras e nos equipamentos Green Key*

Realizar a manutenção preventiva das canalizações

Reparar possíveis fugas de água de imediato

Sustainability Indicators in Foodservice* Sustainability Indicators in Foodservice*

Lista de verificação de boas práticas Enxaguar controladamente, mantendo a torneira fechada na higienização do ambiente, pavimentos, equipamentos, utensílios e alimentos

ambientais para serviços de alimentação 
Tabela 2

Continuação

\begin{tabular}{|c|c|}
\hline \multicolumn{2}{|l|}{ ÁGUA } \\
\hline CRITÉRIO & LISTAGEM(NS) DE ORIGEM \\
\hline Remover bem os restos de comida e descartá-los no lixo adequado, antes de lavar pratos, panelas e utensílios & $\begin{array}{l}\text { Selo Agir Sustentável - Serviços de } \\
\text { Alimentação* }\end{array}$ \\
\hline Manter as caixas ou separadores de gordura em adequado estado de conservação e funcionamento & $\begin{array}{l}\text { Lista de verificação de boas práticas } \\
\text { ambientais para serviços de } \\
\text { alimentação* }\end{array}$ \\
\hline Tratar as águas negras, antes do lançamento no ambiente ou fossa sética no caso de não estar ligado a uma rede de esgoto & $\begin{array}{l}\text { Lista de verificação de boas práticas } \\
\text { ambientais para serviços de } \\
\text { alimentação* }\end{array}$ \\
\hline Tratar de forma eficaz e reutilizar, sempre que possível as águas residuais (águas cinzentas) & Green Globe \\
\hline Recolher, tratar e utilizar a água da chuva, nos autoclismos, para lavar pavimentos, regar ou outros fins adequados & Green Key* \\
\hline $\begin{array}{l}\text { Descongelar os alimentos nas câmaras de refrigeração/frigoríficos, forno de convecção ou micro-ondas e não usar água corrente para } \\
\text { esse efeito }\end{array}$ & $\begin{array}{l}\text { Lista de verificação de boas práticas } \\
\text { ambientais para serviços de } \\
\text { alimentação* }+ \text { Sustainability Indicators } \\
\text { in Foodservice* }\end{array}$ \\
\hline
\end{tabular}

\section{ENERGIA \\ CRITÉRIO}

LISTAGEM(NS) DE ORIGEM

Controlar e medir as fontes com emissões de gases de efeito de estufa (quando possível) e implementar procedimentos para reduzi-las e compensá-las

Instalar contadores de energia inteligentes e verificar os consumos

Green Globe*

Sustainability Indicators in Foodservice*

Instalar contadores separados de eletricidade e gás, nas áreas de maior consumo, para uma melhor monitorização dos consumos

Green Key*

Monitorizar e registar periodicamente os consumos de energia (mensal, semanal, horário, área, equipamento, etc.), indicando as fontes e Green Key* + Food that doesn't cost adotar medidas para diminuir o consumo geral, incentivando o uso de energia renovável

Privilegiar a utilização de energia renovável (eólica, solar ou fotovoltaica, biogás)

the Earth* + Green Globe

Sustainability Indicators in

Foodservice* $^{*}$ Green Key*

Equipar os sistemas de ventilação com um otimizador de energia e um mecanismo de poupança de energia

Green Key*

Programar os sistemas de controlo do aquecimento e de ar condicionado com temperaturas padrão definidas e adaptadas às temperaturas sazonais, e para se desligarem quando não houver ocupação das instalações, ou quando as janelas e portas estiverem abertas

Green Key*

Periodicamente, verificar, reparar se necessário, e limpar os sistemas e equipamentos de ventilação, aquecimento e refrigeração para

serem eficientes em termos energéticos, durante todo o ano

Reduzir o uso de radiadores elétricos, ou outras formas de aquecimento que usem energia elétrica

Instalar um sistema de recuperação de calor para os sistemas de refrigeração, ventilação, piscinas ou águas residuais sanitárias

Realizar a manutenção periódica dos cabos elétricos

(Geen $\log ^{*}$

Green Key

Green Key

Selo Agir Sustentável - Serviços de Alimentação*

Optar pela utilização de lâmpadas LED mais eficientes e económicas e rebaixar as luminárias

Selo Agir Sustentável - Serviços de Alimentação*

Instalar controlos de iluminação, como sensores automáticos e temporizadores, em áreas de baixa ocupação (por exemplo, na área de distribuição) ou no exterior, para que as luzes se acendam / apaguem automaticamente, quando a luz do dia não é / é suficiente ou quando os espaços estão / não estão ocupados

Sustainability Indicators in

Foodservice* + Green Key*

Aproveitar ao máximo a luz natural para iluminar os ambientes

Selo Agir Sustentável - Serviços de Alimentação

Garantir que todos os dispositivos elétricos são energeticamente eficientes Green Key*

Efetuar e documentar as manutenções preconizadas pelos fabricantes dos aparelhos elétricos e eletrónicos, a fim de garantir que todos os equipamentos estejam a funcionar corretamente e mantenham os níveis de eficiência energética

Sustainability Indicators in Foodservice*

Ligar o modo de poupança de energia dos computadores, impressoras e fotocopiadoras para se desligarem automaticamente

Green Key*

Ao adquirir eletrodomésticos, equipamentos como: computadores, impressoras, fotocopiadoras, optar pelos que têm a Etiqueta Energética da União Europeia com classificação mais elevada (a classe energética mais eficiente) e tenham sido produzidos por empresas com sistema de gestão ambiental reconhecido

Optar por equipamentos de refrigeração ou congelação com alarmes sonoros ou fechos automáticos nas portas

Green Key*

Sustainability Indicators in Foodservice*

Instalar cortinas de PVC flexível nas entradas das câmaras de refrigeração ou congelação

Selo Agir Sustentável - Serviços de Alimentação*

Descongelar e limpar os equipamentos de refrigeração regularmente

Green Key*

Sustainability Indicators in

Ter metas instituídas para a redução do uso de combustíveis fósseis (por exemplo: gás liquefeito de petróleo (GPL) / gás natural / gasóleo/gasolina)

odservice* + Sustainability Indicators in Foodservice*

Calafetar todas as janelas e portas para conseguir um isolamento térmico e/ou implementar outras medidas eficientes em termos de energia, de acordo com legislação nacional e adaptadas ao clima local

Green Key*

Garantir que o edifício tem isolamento acima dos requisitos nacionais mínimos de forma a garantir uma redução significativa do consumo de energia

O sistema de canalização de água quente está bem isolado

Green Key

Realizar uma auditoria energética a cada cinco anos

Green Key

Green Key* 
Tabela 2

Continuação

\begin{tabular}{|c|c|}
\hline \multicolumn{2}{|l|}{ CONSUMIVEIS } \\
\hline CRITÉRIO & LISTAGEM(NS) DE ORIGEM \\
\hline $\begin{array}{l}\text { Utilizar, sempre que possível, produtos de limpeza biodegradáveis e não tóxicos para o ambiente e sempre que possível com certificação } \\
\text { ambiental }\end{array}$ & Selo "Dose Certa" - Lipor + Green Key* \\
\hline Comprar a granel e utilizar produtos recarregáveis sempre que possível & Food that doesn't cost the Earth* \\
\hline Comprar vestuário de trabalho feito de fibras recicladas & Food that doesn't cost the Earth* \\
\hline Identificar alternativas reutilizáveis, recicláveis ou mais sustentáveis & Food that doesn't cost the Earth* \\
\hline Evitar usar adubos, pesticidas e fitoquímicos na horta & Sustainability Indicators in Foodservice* \\
\hline $\begin{array}{l}\text { Gerir o uso de produtos químicos de maneira adequada, minimizando o uso de substâncias nocivas, incluindo pesticidas, tintas, } \\
\text { desinfetantes e materiais de limpeza substituindo-os, quando disponível, por produtos inócuos }\end{array}$ & Green Globe* \\
\hline $\begin{array}{l}\text { Optar por papel de impressão e brochuras produzidas ou encomendadas pelo estabelecimento, com certificado ambiental, ou rec } \\
\text { ou produzidos por uma empresa com um sistema de gestão ambiental }\end{array}$ & Green Key \\
\hline
\end{tabular}
ou produzidos por uma empresa com um sistema de gestão ambiental

Disponibilizar louça e/ou utensílios permanentes ou descartáveis biodegradáveis para o uso de clientes ou colaboradores

Selo Agir Sustentável - Serviços de Alimentação*

\section{INSTALAÇÕES E EQUIPAMENTOS \\ CRITÉRIO}

LISTAGEM(NS) DE ORIGEM

Substituir gradualmente as bombas e sistemas de refrigeração que ainda usam como gás refrigerante os CFC ou HCFC. Encaminhar todos os resíduos destes equipamentos para entidades licenciadas

Aproveitar as renovações das instalações como uma oportunidade para substituir por soluções mais eficientes

Green Key*

Optar por móveis, acessórios ou bens duráveis elaborados com materiais recuperados ou reciclados, sempre que possível fornecidos com declaração ambiental de produto

Renovar, reparar e reutilizar mobiliário, acessórios e utensílios

Separar mobiliário, acessórios e utensílios para reciclagem que não se pode reparar ou reutilizar

Usar conceitos e técnicas apropriadas de construção locais e design sustentável, respeitando o ambiente natural e cultural

Utilizar materiais sustentáveis na manutenção, remodelação ou decoração das instalações

Food that doesn't cost the Earth ${ }^{*}+$

Sustainability Indicators in Foodservice*

Sustainability Indicators in

Foodservice $^{*}+$ Green Key*

Food that doesn't cost the Earth+

Sustainability Indicators in Foodservice*

Food that doesn't cost the Earth Green Globe*

Food that doesn't cost the Earth* + Sustainability Indicators in Foodservice + Green Key * Green Key

Todas as áreas de uso exclusivo dos colaboradores devem cumprir com os mesmos critérios que as áreas de clientes Usar baterias recarregáveis para os dispositivos e equipamentos alimentados por baterias, incluindo lanternas, aspiradores de pó de mão e outros

Privilegiar a compra de equipamento de cozinha e outros em segunda mão e remodelados

Privilegiar a contratação de residentes locais, inclusive para cargos de gestão

Garantir políticas de contratação inclusivas

Green Key*

Implementar políticas salariais equitativas e justas

Proposta das autoras

Possuir programas ou formas de valorização dos colaboradores

Selo Agir Sustentável - Serviços de Alimentação*

Green Key*

Green Key*

Green Key*

Green Key*

Selo Saudável + Sustainability Indicators in Foodservice*

Sustainability Indicators in Foodservice*

Green Key*

receção dos alimentos até à sua distribuição

Disponibilizar instruções simples e percetíveis sobre a separação correta dos resíduos, disponíveis para os colaboradores

Formar os colaboradores em matéria de sustentabilidade (eficiência energética, eficiência hídrica, entre outros) 


\begin{tabular}{|c|c|}
\hline CRITÉRIO & LISTAGEM(NS) DE ORIGEM \\
\hline Incentivar os colaboradores a realizar formação complementar & $\begin{array}{l}\text { Selo Agir Sustentável - Serviços de } \\
\text { Alimentação* }\end{array}$ \\
\hline Realização de pelo menos uma campanha anual para promoção da alimentação saudável & $\begin{array}{l}\text { Selo de Excelência "Alimentação } \\
\text { saudável no ensino superior" }\end{array}$ \\
\hline $\begin{array}{l}\text { Implementar uma estratégia de comunicação abrangente para informar visitantes e convidados sobre as suas políticas, programas e } \\
\text { iniciativas sustentáveis }\end{array}$ & Green Globe* \\
\hline Apresentar informações sobre sustentabilidade alimentar no site do restaurante & Green Key* \\
\hline $\begin{array}{l}\text { Praticar educação sustentável (utilizando infográficos, mensagens, informações no menu), incentivando os clientes para a prática de } \\
\text { ações sustentáveis no restaurante (como evitar o desperdício e o uso de descartáveis) e na vida em geral }\end{array}$ & $\begin{array}{l}\text { Selo Agir Sustentável - Serviços de } \\
\text { Alimentação* }\end{array}$ \\
\hline Disponibilizar informação aos clientes sobre transportes públicos, percursos pedestres e ciclovias disponíveis & Green Key* \\
\hline Oferecer aos clientes do restaurante receitas de pratos mediterrânicos que podem coincidir com algumas das especialidades da casa & $\begin{array}{l}\text { Establecimientos Promotores de la } \\
\quad \text { Alimentación Mediterránea }\end{array}$ \\
\hline $\begin{array}{l}\text { Fornecer informações sobre e interpretação do ambiente natural, cultura local e património cultural aos clientes, bem como explicar o } \\
\text { comportamento adequado ao visitar as áreas naturais, as culturas vivas e os locais de património cultural }\end{array}$ & Green Globe* \\
\hline $\begin{array}{l}\text { Cumprir com a legislação internacional, nacional e local e ter uma política de responsabilidade social que integre as áreas do ambiente, } \\
\text { saúde, segurança e trabalho }\end{array}$ & Green Key* \\
\hline Definir um plano de ação anual e objetivos para a melhoria contínua & Green Key* \\
\hline $\begin{array}{l}\text { Assegurar que os fornecedores possuem certificação ambiental, têm uma política ambiental escrita e/ou estão comprometidos com o } \\
\text { desenvolvimento sustentável }\end{array}$ & Green Key* \\
\hline Ter compromissos para atingir zero emissões de gases de efeito de estufa & Sustainability Indicators in Foodservice* \\
\hline Possuir uma política operacional que contenha uma estratégia documentada de gestão de resíduos sólidos (não alimentares) & Sustainability Indicators in Foodservice* \\
\hline Adquirir produtos (alimentares ou não alimentares) elaborados por instituições que contribuam para um impacto social positivo & Sustainability Indicators in Foodservice* \\
\hline Medir a satisfação dos clientes e aplicar ações corretivas quando apropriado & Green Globe* \\
\hline Garantir a acessibilidade a pessoas com mobilidade reduzida & Green Key* \\
\hline $\begin{array}{l}\text { Apoiar atividades ambientais ou iniciativas para o desenvolvimento sustentável da comunidade local, em áreas como a educação, saúde, } \\
\text { saneamento e infraestruturas }\end{array}$ & Green Key* \\
\hline Recolher e doar os materiais/produtos que já não são usados pelo estabelecimento a organizações de solidariedade social & Green Key* \\
\hline $\begin{array}{l}\text { Organizar atividades de educação ambiental para a sustentabilidade dirigidas a clientes, colaboradores, comunidade e/ou parceiros nas } \\
\text { instalações do estabelecimento ou no exterior }\end{array}$ & Green Key* \\
\hline $\begin{array}{l}\text { Oferecer os meios para que pequenos empreendedores locais desenvolvam e vendam produtos sustentáveis que são baseados na } \\
\text { natureza, história e cultura da área (incluindo comida e bebida, artesanato, manifestação artística, produtos agrícolas, etc.) }\end{array}$ & Green Globe* \\
\hline Contribuir para o apoio à conservação da biodiversidade, incluindo o apoio a áreas naturais protegidas e áreas de alto valor de biodiversidade & Green Globe* \\
\hline
\end{tabular}

* Critérios adaptados da formulação inicial

** Critérios adaptados do Green Public Procurement

\section{DISCUSSÃO DOS RESULTADOS}

Este trabalho é o primeiro que compila um conjunto alargado de critérios sobre sustentabilidade, aliando conceitos de circularidade dos fluxos, produção sustentável e do Padrão Alimentar Mediterrânico, para serem aplicados à dinâmica de um restaurante, de forma a promover o conceito de Restaurante Sustentável. Existem diversas listagens de critérios que frequentemente servem de base para a atribuição de selos ligados ao conceito da sustentabilidade, mas nenhum apresenta a abrangência da listagem que este trabalho promove. Por esta mesma razão, a listagem proposta é composta por um número de critérios bastante superior a cada uma das 13 listagens recolhidas, indicadas previamente (4 critérios na lista mais pequena e 117 critérios na listagem mais extensa), visto conter 160 critérios. Desta forma, entendeu-se, apresentar uma visão bastante completa do conceito de sustentabilidade, envolvendo todas as suas dimensões (ambiental, social e económica), desde a produção ao consumo, o que permitirá aos restaurantes obter uma visão mais alargada do mesmo. Esta listagem representa uma revisão extensa, que se apresenta dividida em nove domínios, facilitando a interpretação da listagem total, fornecendo aos gestores dos restaurantes propostas de ações concretas sobre cada um dos domínios, podendo funcionar como um quadro de referência para a realização de checklists de aplicação prática.

Um dos elementos diferenciadores da abordagem seguida advém da integração do conceito de Economia Circular que se materializa no
DOP: Denominação de Origem Protegida IGP: Indicação Geográfica Protegida

agrupamento por fluxos (de materiais, energia e água) $(31,43)$. De notar, que foi eliminado o domínio de Gestão de Resíduos, existente em listagens como o Green Key, e que foram incorporados critérios relativos a estratégias de gestão de fim de vida em cada um dos domínios aplicáveis. Para além disso, os critérios focam mais estratégias de prioridade superior (reutilização, reparação) do que reciclagem. A Economia Circular serve de inspiração para uma sustentabilidade sem desperdício, na qual os ciclos de materiais são fechados. A visão de transformação sistémica que a transição para uma economia mais circular exige, está também patente em critérios que refletem soluções não massificadas em Portugal como é o caso das embalagens de takeaway retornáveis.

Neste trabalho, só foi utilizada uma listagem que tem por base princípios de Economia Circular ("Food that doesn't cost the Earth", do Reino Unido), uma vez que apesar de já existirem várias metodologias de análise de circularidade (ex: "Circularytics", Ellen MacArthur Foundation (44); "Circularity Check", Ecopreneur (45)), nenhuma é aplicável a restaurantes.

É do nosso conhecimento, que estão a ser desenvolvidas, atualmente, ferramentas de análise de circularidade a nível europeu ou Português, aplicadas à Restauração (a ferramenta "Circularity Check" poderá vir a desenvolver uma versão aplicada ao setor da restauração; no âmbito do projeto City Loops (46), a Câmara Municipal do Porto está a desenvolver com o apoio da Lipor, uma ferramenta com enfoque na prevenção 
de bio-resíduos em restaurantes), que poderão ser aplicadas como ferramentas internas que auxiliem a transição.

Outro elemento diferenciador da listagem de critérios apresentada neste trabalho tem a ver com a identificação de um domínio adstrito à produção alimentar. Tendo em conta que a avaliação de ciclo de vida dos alimentos conclui frequentemente que a produção é a fase que representa maior impacte ambiental do produto alimentar (47), é também importante realçar este aspeto junto dos restaurantes, apresentando-Ihes critérios que auxiliem a escolhas mais conscientes. Neste domínio, é dado particular enfoque à escolha de produção local, sazonal e de cadeias curtas. A tendência para um consumo sustentável cria oportunidades de mercado para as produções agrícolas locais e constitui um potencial que pode ser utilizado beneficiando agricultores, consumidores, territórios e acima de tudo o ambiente. Ao adquirirem produtos locais, os restaurantes promovem o consumo, por parte dos seus clientes, de produtos diversificados, frescos e de época e com um valor nutricional potencialmente superior. É, pois também, uma forma de estabelecer uma ligação direta com os agricultores, conhecendo a origem e as condições de produção. Relativamente aos territórios, a venda direta permite fixar o valor económico destas produções favorecendo o desenvolvimento local. O consumo de alimentos de produção local favorece as cadeias de fornecimento curtas ou diretas, evitam o transporte dos produtos agrícolas em grandes distâncias, o que leva à redução de emissões de gases de efeitos de estufa. Assim, os circuitos curtos representam uma oportunidade para a produção, comercialização e consumo alimentar locais, valorizado através de um conjunto de benefícios de caráter ambiental, social, cultural e económico (48). Ao contrário de outros Estados-membros (49), em Portugal não existe uma definição para a distância que determina a produção local, no entanto, considerou-se a distância de 75 km, com base na recomendação presente do documento de orientações da União Europeia relativas aos auxílios estatais nos setores agrícola e florestal e nas zonas rurais para 2014-2020 (50). Contudo, é de considerar os desafios que este limite pode impor, sobretudo em grandes centros urbanos, onde a produção alimentar de proximidade pode não conseguir suprir as necessidades de determinados restaurantes, o que pode dificultar a definição de ementas tendo em conta este aspeto, sobretudo no que respeita à gestão das quantidades disponíveis.

Na última década, a agricultura sustentável em modo de produção biológica na União Europeia cresceu cerca de meio milhão de hectares por ano, assumindo-se cada vez mais como uma oportunidade, pois trata-se de uma prática que envolve preocupações ambientais, económicas e sociais. Portugal tem acompanhado esta tendência, surgindo uma nova geração de adeptos (produtores e consumidores) mais atentos às questões de saúde, de bem-estar e de sustentabilidade ambiental, e que têm contribuído para o desenvolvimento da produção sustentável (51). Apesar de se encontrar um pouco à margem dos problemas causados pela intensificação da agricultura convencional, o consumidor português está a inclinar-se, aos poucos, para alimentos sem pesticidas. Tal mudança prende-se com as questões relacionadas com a segurança alimentar, pela procura por produtos com maior valor nutricional e sabor e pela crescente preocupação com a sustentabilidade dos ecossistemas (52). Desta forma, os restaurantes podem ser aliados desta tendência, procurando inserir nas suas ementas produtos que sejam provenientes de uma produção mais sustentável. Contudo, será importante promover um maior envolvimento do restaurante com os fornecedores dos produtos alimentares, de forma a conhecerem de perto os modelos de produção, pelo que se incluiu um critério proposto pelas autoras onde isto é referenciado.

Além disso, entendeu-se ser importante ajustar o domínio da produção alimentar aos critérios do Green Public Procurement (42). Não sendo esta uma listagem de critérios destinada ao setor da restauração privada, não foi incluída na aglomeração inicial de critérios, mas permitiu na fase final rever e ajustar alguns critérios existentes ou formulados de novo, como é exemplo o critério referente à seleção dos ovos, alimento muito usado na gastronomia nacional e europeia e que não figurava em nenhuma das listagens selecionadas. Apesar de ser importante ajustar os critérios do Green Public Procurement à realidade de cada país (53), havendo já essa adaptação para Portugal (54), optou-se por se usar os critérios do documento original para a análise e adaptação efetuadas. Por outro lado, no contexto de sustentabilidade alimentar, onde está implícita a promoção de uma alimentação saudável, pareceu-nos importante procurar adicionar critérios que tornassem a ementa equilibrada sob o ponto de vista alimentar e nutricional e que conduzisse à redução do desperdício alimentar, desde a preparação, confeção e serviço das refeições. Sendo o Padrão Alimentar Mediterrânico considerado um dos mais saudáveis, bem como um dos mais sustentáveis $(19,20)$, incluíram-se os critérios de adesão à Rede de Estabelecimentos promotores da Alimentação Mediterrânica, existente em Espanha. Os critérios apresentados podem ser um ponto de partida para uma auto-análise por parte dos restaurantes ou para a construção de um conceito de raiz. Contudo, dado o afastamento atual dos países do Mediterrâneo do modelo alimentar que os caracterizava (55), estima-se que a oferta alimentar da maioria dos restaurantes também siga a mesma tendência, pelo que se prevê que o cumprimento ou adesão a estes critérios possa ser difícil e alvo de um processo paulatino. Será igualmente importante incrementar a literacia alimentar da população, que Ihe permita fazer uma avaliação adequada da oferta alimentar dos restaurantes e que possa contribuir para uma maior procura de ofertas mais equilibradas, de forma a também permitir com isso potenciar o aumento da sua disponibilidade. Efetivamente, se existir um cuidado na seleção de alimentos que causem um menor impacte ambiental pela sua natureza ou pelo seu modo de produção, será também importante promover a escolha de confeções culinárias que preservem melhor os nutrientes dos alimentos e que garanta uma utilização integral dos mesmos, reduzindo o desperdício alimentar, a par do respeito pela sazonalidade, frescura e produção de proximidade. Com base nesta lógica, procurou-se ainda adicionar propostas de critérios efetuadas pelas autoras que fossem mais além e abordassem a questão da quantidade de alimentos presente em cada dose servida, bem como a proporção entre os grupos alimentares, indo de encontro ao que se advoga no projeto Dose Certa da Lipor (36), apelando-se à consulta das orientações da Roda da Alimentação Mediterrânica, no caso de restaurantes portugueses (56), apesar de se assumir que podem traduzir objetivos ambiciosos, uma vez que a sua operacionalização pode ser de difícil execução, dada a atual oferta alimentar mais distanciada de um modelo alimentar Mediterrânico. Por outro lado, atendendo ao crescente interesse e promovendo a literacia do consumidor, propôs-se que as ementas possam funcionar como veículos de informação mais detalhada sobre o que é servido, podendo, assim, incluir a declaração nutricional e/ou outras ferramentas que permitam um maior conhecimento sobre a oferta gastronómica e o valor do impacte ambiental de cada sugestão gastronómica apresentada (medida em pegada de carbono ou outra avaliação).

Será importante disponibilizar ferramentas que contribuam para um melhor conhecimento do alimento e que foquem cada vez mais a abordagem nos alimentos e menos nos nutrientes. Destaca-se um exemplo de uma ferramenta que foi recentemente publicada por Viegas, C e Rocha, A e que permite de uma forma simplificada e gráfica dar informação sobre o cumprimento das recomendações alimentares da Roda dos Alimentos, 
podendo este infográfico ficar disponível nos menus e assim potenciar escolhas mais conscientes (57). Paralelamente poderá ser criada a oportunidade de mudar o paradigma da valorização da componente proteica de origem animal na designação dos pratos, promovendo-se o realce dos alimentos de origem vegetal, como tinha sido já sugerido por outros autores (58).

Outro aspeto de reflexão neste trabalho foram as Embalagens, usadas no contexto alimentar e não alimentar. A utilização de embalagens de takeaway, tipicamente descartáveis, é uma das práticas que gera mais desperdício de materiais não alimentares em restaurantes. Uma maior consciência deste impacte ambiental, poderá incentivar os restaurantes a promoverem sistemas de reutilização de embalagens e de utilização de materiais biodegradáveis, à semelhança do que já acontece em projetos já implementados no mercado, como o caso do Embrulha, da Lipor (35). Será necessário ter em consideração a legislação específica aplicada a embalagens que entram em contato com alimentos, na aplicação de práticas nesta área. Além disso, será importante realizar estudos que permitam perceber qual a opção mais sustentável em termos ambientais e qual o custo e o impacto sobre o que paga o consumidor, de forma a melhor caracterizar a viabilidade de aplicação destas medidas.

Os restaurantes são também locais de consumo de bens essenciais cada vez mais escassos, como o caso da água, pelo que cada vez mais deve ser feita uma sensibilização para o seu uso muito regrado, de acordo com o Relatório Mundial das Nações Unidas sobre Desenvolvimento dos Recursos Hídricos, 2020 (59). Pretendeu-se assim, com a seleção dos critérios relacionados com o consumo da Água, aumentar a eficiência no seu uso, sensibilizar e reduzir o consumo desnecessário e a perda de água. Uma maior eficiência hídrica traduz-se em menor consumo de energia e, portanto, menores emissões de gases de efeito de estufa, pois na gestão da água e do saneamento estão envolvidas também uma grande parte das emissões destes gases devido à energia utilizada para alimentar os sistemas, a dessalinização, ou os processos bioquímicos envolvidos no tratamento da água e das águas residuais (60). Estas ações pretendem ir ao encontro do ODS 6 - Água Potável e Saneamento, nomeadamente as metas 6.3 e 6.4 que pretendem até 2030 respetivamente "melhorar a qualidade da água, reduzir a poluição, eliminar o despejo e minimizar a libertação de produtos químicos e materiais perigosos, reduzindo para metade a proporção de águas residuais não tratadas, e aumentar substancialmente a reciclagem e reutilização segura globalmente" e "aumentar substancialmente a eficiência do uso da água em todos os setores e assegurar extrações sustentáveis..." (13).

O domínio da Energia assume um papel importante na melhoria da sustentabilidade dos restaurantes, através do consumo mais eficiente e da redução do desperdício energético, tendo um impacto económico direto (os consumos energéticos em serviços alimentares representam entre 4 a $6 \%$ dos custos operacionais) (23). O mesmo estudo indica que $60 \%$ da energia usada na cozinha de restaurantes é perdida. Também as fontes de energia usadas pelos estabelecimentos são relevantes para a sua pegada carbónica. As ações propostas enquadram-se no âmbito do ODS 7 - Energia Limpa, nomeadamente no que concerne os objetivos 7.2 e 7.3 que pretendem até 2030, "aumentar substancialmente o peso das energias renováveis no consumo energético total" e "dobrar a taxa de melhoria de eficiência energética globalmente" (13). Contudo, apesar de as medidas apresentadas serem fundamentais, será importante realçar que para os domínios da "água", da "energia" e das "instalações e equipamentos" é proposto um conjunto de critérios cujos desafios de aplicabilidade são vários, podendo ser mais difíceis de desenvolver num restaurante associado a uma micro ou pequena empresa, que representa quase a totalidade do setor em Portugal, como previamente apresentado. Desta forma, o conjunto de critérios apresentados poderá ser de maior interesse sobretudo num contexto de criação de um novo conceito e abertura de um novo restaurante, pois permite o planeamento e desenvolvimento dos recursos necessário de base.

No que concerne ao domínio destinado aos Transportes, os critérios incluídos sugerem práticas mais sustentáveis, quer ao nível de alternativas de modos de transporte, quer em termos de eficiência (para além da energética). No entanto, considerando que se ao nível da produção alimentar (o maior volume e frequência de bens que são transportados para um restaurante), for seguida a orientação da produção local num raio máximo de $75 \mathrm{~km}$, poderão ser minimizadas muitas emissões de gases de efeito de estufa, por esta via.

Por fim, e uma vez que o impacto das ações que estimulem alterações alimentares é potencialmente superior ao das soluções tecnológicas implementadas na fase de produção, identifica-se uma oportunidade para que os restaurantes e seus colaboradores sejam veículos de educação alimentar/sensibilização ambiental dos consumidores (61). Estas preocupações com a sustentabilidade dos restaurantes não se devem cingir só aos alimentos, mas também aos consumíveis e outros materiais utilizados no seu dia-a-dia procurando sempre soluções que respeitem o ecossistema. É fundamental que restaurantes e suas equipas percecionem que o ser um "restaurante sustentável" constitui uma oportunidade de mercado beneficiando não só os seus clientes, mas também toda a cadeia de valor associada. A crescente preocupação do consumidor com a saúde, bem-estar e questões ambientais tem levado a uma maior procura por produtos mais saudáveis e por espaços com ofertas sustentáveis, demonstrando mais uma vez, a emergência de restaurantes com práticas mais circulares. Desta forma, também todos os colaboradores devem ser devidamente formados para poderem transmitir aos clientes informações corretas e alinhadas com as políticas sustentáveis implementadas pelo restaurante. De salientar ainda o papel que o restaurante deve pressentir ter na comunidade em que se insere. Da mesma forma que o restaurante se adapta à realidade local, através do uso de alimentos de proximidade, de fornecedores da comunidade e de recuperação/redefinição da cultura alimentar, também pode ter um papel na comunidade, através da promoção das atividades, cultura e pessoas inseridas neste contexto, bem como de outras entidades e projetos. É importante que o restaurante tenha a noção de comunidade e da sua influência na comunidade e da mesma em si.

Atualmente são muitas as iniciativas que procuram realçar e incentivar as práticas mais sustentáveis nos restaurantes. A par dos diversos projetos já elencados previamente e dos diversos selos e listagens existentes, são vários os projetos que têm vindo a proliferar, de onde pode ser destacada a distinção efetuada pelo Guia Michelin, que tem vindo a premiar a sustentabilidade dos restaurantes (62). Desde 2014 é ainda identificado anualmente o restaurante mais sustentável do Mundo, tendo sido em 2019 reconhecido o Restaurante Schloss Schauenstein, na Suíça, com esta distinção (63). Em Portugal, mais recentemente, a Associação da Hotelaria, Restauração e Similares de Portugal lançou um guia de boas práticas para uma restauração circular e sustentável, de forma a auxiliar os restaurantes na transição para um modelo de negócio mais próximo dos princípios da economia circular (64).

Pretende-se que a listagem identificada neste trabalho represente, numa primeira fase, um conjunto de boas práticas que os restaurantes possam seguir e implementar; ou melhorar as práticas já existentes; ou até medir aquilo que já desenvolvem de forma a estabelecer metas a cumprir. Contudo, no futuro, esta listagem poderá constituir a base para uma validação por especialistas do setor e posterior validação do seu conteúdo, como se verificou no trabalho de Maynard et al. (41). No seguimento desse processo, esta listagem poderia até evoluir 
para a base de um selo ou uma certificação a atribuir aos restaurantes que apresentassem as melhores práticas de sustentabilidade. Neste contexto, poderia ser identificada uma percentagem mínima de critérios a ser cumprida dentro de cada domínio e, eventualmente poderiam ser identificados os critérios de cumprimento obrigatório dentro de cada domínio. Poderiam também ser identificados objetivos quantitativos a serem alcançados anualmente, e verificados em sede de auditoria. Vivemos tempos em que a redução de danos ao meio ambiente não deve ser encarada como um diferencial competitivo ou como um ato de caridade, mas sim como uma necessidade para garantir a sobrevivência das gerações futuras. Os restaurantes podem ser aliados importantes nesta equação, sendo, por isso, importante desenvolver ferramentas como a que se apresenta neste trabalho para se facilitar a implementação do conceito de sustentabilidade por estas entidades.

\section{CONCLUSÕES}

Urge promover uma reformulação do sistema alimentar, envolvendo todos os agentes, onde os restaurantes representam um pape importante. Promover a sustentabilidade, desde a produção ao consumo neste setor é algo que começa a ser uma realidade, mas que importa realçar e criar ferramentas que auxiliem neste processo. O desafio traduz-se, muitas vezes, pelo desconhecimento de como realizar as intervenções, em simultâneo com a escassez de recursos que habitualmente estão disponíveis. Desta forma, este artigo apresenta uma revisão extensa, materializada numa listagem de 160 critérios de sustentabilidade, divididos por nove domínios, pretendendo representar uma ferramenta, enquanto quadro de referência para a realização de checklists de aplicação prática, que auxilie os restaurantes num processo de reestruturação do seu modelo ou num processo de construção de um novo conceito. Destaca-se, contudo, que apenas com o envolvimento de todos, desde a gestão de topo até ao colaborador com funções mais simples, onde todos têm um papel a desempenhar, contribuindo cada um com o respetivo desempenho e responsabilidade, se consegue atingir o objetivo final: maior sustentabilidade dos recursos e, consequentemente, do nosso planeta.

\section{REFERÊNCIAS BIBLIOGRÁFICAS}

1. Willett W, Rockstrom J, Loken B, Springmann M, Lang T, Vermeulen S, et al. Food in the Anthropocene: the EAT-Lancet Commission on healthy diets from sustainable food systems. Lancet (London, England). 2019;393(10170):447-92.

2. Poore J, Nemecek T. Reducing food's environmental impacts through producers and consumers. Science (New York, NY). 2018;360(6392):987-92.

3. C40 Cities AUoL. Addressing food-related consumption-based emissions in C40 Cities - In focus. 2019.

4. WWF. Living Planet Report 2020 - Bending the curve of biodiversity loss. . Gland, Switzerland: WWF; 2020.

5. FAO. The State of Food and Agriculture 2019. Moving forward on food loss and waste reduction. . Rome; 2019.

6. Candari CJ CJ, Nolte E. . Assessing the economic costs of unhealthy diets and low physical activity: An evidence review and proposed framework. . WHO Regional Office for Europe; 2017.

7. Global, regional, and national comparative risk assessment of 84 behavioural, environmental and occupational, and metabolic risks or clusters of risks, 1990-2016: a systematic analysis for the Global Burden of Disease Study 2016. Lancet (London, England). 2017;390(10100):1345-422.

8. Health effects of dietary risks in 195 countries, 1990-2017: a systematic analysis for the Global Burden of Disease Study 2017. Lancet (London, England) 2019;393(10184):1958-72
9. Programme UNE. Food Waste Index Report 2021. 2021

10. United Nations DoEaSA, Population Division. World Population Prospects 2017 Data Booklet (ST/ESA/SER.A/401). 2017.

11. Wrap. An overview of waste in the UK hospitality and food service sector. 2013.

12. Division UNDoEaSAP. World Population Prospects The 2017 Revision. 2017.

13. Development UNDoEaSAS. 17 Sustainable Development Goals [Available from: https://sdgs.un.org/goals.

14. Commition E. Farm to Fork Strategy - for a fair, healthy and environmentally-frien-

dly food system. 2020 .

15. Commition E. Communication from the Commission to the European Parliament, the European Council, the council, the European Economic and Social Committee and the Committee of the regions. The European Green Deal

COM/2019/640 final. Brussels; 2019.

16. Commition E. A new Circular Economy Action PlanFor a cleaner and more competitive Europe. 2020

17. FAO. Sustainable Food Systems - Concept and Framework. 2018.

18. Real H, Dias RR, Graça P. Mediterranean Diet conceptual model and future trends of its use in Portugal. Health promotion international. 2020.

19. Dernini S, Berry EM. Mediterranean Diet: From a Healthy Diet to a Sustainable Dietary Pattern. Frontiers in nutrition. 2015;2:15.

20. Dernini S, Berry EM, Serra-Majem L, La Vecchia C, Capone R, Medina FX, et al. Med Diet 4.0: the Mediterranean diet with four sustainable benefits. Public health nutrition. 2017;20(7):1322-30.

21. Truninger Mc, Schmidt Lc, Fonseca S, Graça J, Junqueira L, Prista P. $2^{\circ}$ Grande Inquérito sobre Sustentabilidade em Portugal, 2019. 2019.

22. Board LwR. FoodSave key stats.

23. Trust C. Food preparation and cateringlncrease carbon savings without compromising on quality. 2008

24. Restaurante A Cozinha [Available from: https://restauranteacozinha.pt/]

25. Restaurante Kitchen Dates [Available from: https://kitchendates.pt/].

26. Nolla Restaurant [Available from: https://www.restaurantnolla.com/].

27. Silo Restaurant [Available from: https://silolondon.com].

28. Azurmendi Restaurant [Available from: https://azurmendi.restaurant/]

29. Estudos GdEe. Síntese estatística sectorial - Alojamento, restauração e similares - restaurantes. Ministério da Economia e Transição Digital; 2021.

30. Amed de establecimientos promotores de la Alimentación Mediterránea [Available from: http://www.amed.cat/home.php].

31. Food that doesn't cost the earth [Available from: https://advancelondon.org/news-events/food-that-doesnt-cost-the-earth/].

32. Green Globe [Available from: https://greenglobe.com/standard/]

33. Green Key [Available from: https://greenkey.abae.pt/].

34. Luciléia Granhen Tavares Colares VdOF, Aline Alves Ferreira, Aline Gomes de Mello de Oliveira. Good environmental practices check list for food services: elaboration, content validation and inter-rater reliability. Braz J Food Technol. 2018;21(e2017066). 35. Embrulha. e os seus restaurantes à distância de um clique! [Available from: https:// www.lipor.pt/pt/noticias/embrulha-e-os-seus-restaurantes-a-distancia-de-um-clique/]. 36. Dose Certa [Available from: https://www.lipor.pt/pt/sensibilizar/100-desperdicio/ desperdicio-alimentar/].

37. Restaurantes FOOD [Available from: http://www.food-programme.eu/pt/ferramentas/article/recomendacoes].

38. Agir Sustentável [Available from: https://agirsustentavel.com.br/]

39. Alimentação saudável no ensino superior -selo excelência [Available from: https:// nutrimento.pt/noticias/alimentacao-saudavel-no-ensino-superior-selo-excelencia/].

40. DGS CMdL. Manual "Selo Saudável". 2016.

41. Maynard D da C ZR, Nakano EY, Botelho RBA. . Sustainability Indicators in Restaurants: The Development of a Checklist. Sustainability 2020;12:4076.

42. Commition E. EU green public procurement criteria for food, catering services and vending machines. Brussels; 2019.

43. Stahel WR. The circular economy. Nature [Internet]. 2016. [Available from: https:// www.nature.com/news/the-circular-economy-1.19594]. 
44. Foundation EM. Circulytics - the new digital tool which accurately measures circularity [Available from: https://www.ellenmacarthurfoundation.org/news/circulytics-the-new-digital-tool-which-allows-businesses-to-accurately-measure-the-success-of-their-circular-initiatives].

45. Ecopreneur. How circular are the products and services your company puts on the market? [Available from: https://ecopreneur.eu/circularity-check-landing-page/]. 46. Cityloops [Available from: https://cityloops.eu/cities/porto].

47. Gheewala SH, Jungbluth N, Notarnicola B, Ridoutt B, van der Werf H. No simple menu for sustainable food production and consumption. The International Journal of Life Cycle Assessment. 2020;25(7):1175-82.

48. MAMAOT. Estratégia para a Valorização da Produção Agrícola Local. Relatório Final do Grupo de Trabalho GEVPAL. Lisboa: Ministério da Agricultura, Mar, Ambiente e Ordenamento do Território; 2013.

49. Kneafsey M, Venn, L. , Schmutz, U. , Balázs, B. , Trenchard, L. , Eyden-Wood, P. , Bos, E. ,, Sutton GaB, M. . Short food supply chains and local food systems in the EU: A state of play of their socio-economic characteristics. European Commission; 2013. 50. Europeia U. Orientações da União Europeia relativas aos auxílios estatais nos setores agrícola e florestal e nas zonas rurais para 2014-2020 Jornal Oficial da União Europeia. 2014;C204.

51. Ferreira C. Avaliação do impacto das ações de formação em agrocultura biológica na Lipor. Instituto Politécnico de Viana do Castelo2017.

52. Truninger M. O Campo Vem à Cidade: Agricultura Biológica, Mercado e Consumo Sustentável. Lisboa: Imprensa de Ciências Sociais; 2010.

53. Neto B. Analysis of sustainability criteria from European public procurement schemes for foodservices. Science of The Total Environment. 2020;704:135300.

54. APA. Estratégia Nacional para as Compras Públicas Ecológicas [Available from: https://encpe.apambiente.pt/content/sobre.

55. Vilarnau C, Stracker DM, Funtikov A, da Silva R, Estruch R, Bach-Faig A. Worldwide adherence to Mediterranean Diet between 1960 and 2011. European journal of clinical nutrition. 2018.

56. DGS F, DGC. A Roda da Alimentação Mediterrânica [Available from: https://nutrimento.pt/cartazes/a-roda-da-alimentacao-mediterranica/.

57. Viegas C, Rocha A. Menos nutrientes e amis alimentos: proposta de abordagem para escolhas conscientes. Acta Portuguesa de Nutrição. 2020(23):70-5.

58. Rocha A, Viegas C. Repensar a descrição dos menus: um novo paradigma como um caminho para mais saúde e mais sustentabilidade 2019 [Available from: https:// pensarnutricao.pt/repensar-a-descricao-dos-menus-um-novo-paradigma-como-um-caminho-para-mais-saude-e-mais-sustentabilidade/].

59. UNESCO U-W. United Nations World Water Development Report 2020:Water and Climate Change. Paris; 2020.

60. Council NRD. Water Efficiency Saves Energy: Reducing Global Warming Pollution Through Water Use Strategies. 2009.

61. Cucurachi S, Scherer L, Guinée J, Tukker A. Life Cycle Assessment of Food Systems. One Earth. 2019;1(3):292-7.

62. MICHELIN Guide 2020: The New Sustainability Emblem [Available from: https:// guide.michelin.com/en/article/news-and-views/michelin-guide-2020-the-new-sustainability-emblem].

63. Sustainable Restaurant Award [Available from: https://www.theworlds50best.com/ awards/sustainable-restaurant-award].

64. Portugal Td. Apresentação do guia de boas práticas para uma restauração circular e sustentável. 2021. 